grupos nativos não cristianizados. Apesar da intensa atividade de ensino universitário nos anos iniciais do SIL no Brasil, a produção linguística dos integrantes da organização se mostra exígua, diante da quantidade de anos e de grupos indígenas com os quais trabalharam. Isto porque, a partir de 1969, o SIL passou a tratar diretamente com a Funai, apoiando-se basicamente na questão da alfabetização. A qualidade da maior parte dos trabalhos estava limitada pelo objetivo maior de reduzir a língua à forma ortográfica, necessária para a tradução da Bíblia. Segundo Leite, os resultados práticos do empreendimento são cartilhas nas quais a língua indígena aparece esvaziada de qualquer relevância e conexão com a vida indígena, trazendo muitas vezes conteúdo propagandístico do Estado brasileiro durante o período dos convênios oficiais, encerrados em 1977.

Em "O português brasileiro, uma língua criola", a autora comenta a hipótese da influência do substrato indígena na formação do português nacional. Dois focos importantes são tratados no decorrer do artigo: o papel das línguas francas de origem tupi (como o tupinambá e o nheegatu amazônico) e o português falado por indígenas em regiões multilíngues, como o Parque do Xingu. A autora conclui que certos fenômenos encontrados no português brasileiro (como a falta de concordância sujeito/verbo) não poderiam se dever ao substrato indígena em virtude das diferenças linguísticas substanciais existentes, geralmente apagadas através da categoria supraétnica "índio".

Assim, os textos selecionados de Yonne Leite possuem valor de memória sobre a pesquisa em terras indígenas e registro histórico sobre a conformação mútua dos campos da Linguística e da Etnologia no Brasil, além das discussões específicas sobre as línguas tapirapé e araweté que beneficiariam estudiosos dos povos Tupi.
No entanto, os artigos conduzem ainda o leitor para a reflexão sobre o papel político do estudo das línguas indígenas no Brasil: atores, motivações e implicações, o que só aumenta o alcance e a importância da obra de Yonne Leite para pesquisadores das duas disciplinas.

DOI http://dx.doi.org/10.1590/0104-93132015v21n1p226

ROCHA, Lia de Mattos. 2013. Uma favela "diferente das outras"? Rotina, silenciamento e ação coletiva na favela do Pereirão, Rio de Janeiro. Rio de Janeiro: Quartet \& Faperj. 292 pp.

\section{Daniela Fichino}

Pesquisadora na Justiça Global

Uma favela típica da exceção, um caso particular do possível, "bom para pensar". No Rio de Janeiro anterior ao início da implantação das Unidades de Polícia Pacificadoras (UPPs), a favela do Pereirão poderia ser tomada como uma "ilha de tranquilidade" em meio a um cenário de incursões policiais e confrontos - como uma favela "diferente das outras"? Que oportunidades e obstáculos esta suposta "tranquilidade" ofereceria à ação coletiva dos moradores e à atuação das organizações locais e supralocais que existem no âmbito da favela? Seria um cenário suficiente para afastar as representações que estigmatizam os moradores e os confundem com traficantes de drogas e, consequentemente, alterar o grau de interlocução possível que detêm no espaço público?

Tais questões, aqui simplificadamente colocadas, são o ponto de partida para o cuidadoso trabalho de pesquisa realizado por Lia Rocha na Vila Pereira da Silva, ou simplesmente "Pereirão", favela localizada na zona sul da cidade do Rio de Janeiro. Dialogando com uma extensa 
literatura sobre as favelas cariocas, a autora apresenta nas páginas iniciais um detido relato sobre o histórico de representações que recaem sobre esses territórios da cidade. "A história das favelas cariocas está fortemente relacionada com a identificação delas como um 'problema'" (:18), descreve a autora, que reconstrói o percurso de alteração do tipo e da dimensão do "problema" em diferentes momentos históricos, até sua formulação atual: a favela como um "problema de segurança pública".

Evidenciar o tipo de representação (e de "problema") hoje associado às favelas apresenta-se como um movimento central para o argumento da autora, que identifica a partir daí restrições para a ação coletiva dos moradores dessas localidades. O controle e o cerceamento que os traficantes muitas vezes impõem às associações de moradores de favelas conduzem à perda de legitimidade de suas lideranças, que passam a ser identificadas como porta-vozes de interesses criminosos (:20). Neste cenário, novos atores e estratégias surgem como alternativas de legitimação da voz dos moradores de favelas perante as arenas públicas. Mas como compreender esta dinâmica em uma favela "tranquila", supostamente livre do controle territorial armado imposto às populações faveladas da cidade?

O primeiro capítulo do livro dedica-se a explorar o sentido da "tranquilidade" do local, mencionada e reforçada nos discursos dos moradores, em contraste com um cenário de recorrentes incursões policiais e confrontos entre a polícia e grupos de traficantes nas favelas da cidade. Segundo a autora, a construção local da categoria "tranquilidade" é produto de diferentes eventos encadeados: o assassinato do principal traficante local e a consequente instalação de uma iniciativa-piloto da Secretaria de Segurança do Estado chamada "Mutirão pela Paz", em
1999, de breve duração, cujo mote principal centrava-se na "ocupação social" da favela em oposição às "ocupações" policiais (:51), além da transferência da sede do Batalhão de Operações Policiais Especiais (Bope) para a vizinhança da favela, em 2000 (:66). Esta conjunção de fatores teria permitido um ambiente propício para a "inexistência do tráfico de drogas ou, pelo menos, para uma composição mais subterrânea e intersticial dessa atividade, e assim menos ameaçadora da vida cotidiana dos moradores" (:66), situação que perdurava até o período de realização do trabalho de campo para a pesquisa, entre os anos de 2005 e 2008.

A excepcionalidade da favela como um local "tranquilo" - uma favela supostamente "diferente das outras" - foi repetidamente mencionada pelos moradores no decorrer da pesquisa. Mas a construção nativa da "tranquilidade" como um fator estruturante da rotina e da sociabilidade na favela coexiste com o medo e o silêncio dos moradores que, conforme as observações da autora, se orientam pelas mesmas regras impostas em favelas onde os traficantes têm presença ostensiva (:87). O discurso da "tranquilidade", conclui, converte-se então em uma versão local da "lei do silêncio", uma obediência escamoteada e sub-reptícia às "regras do tráfico", seja por temor de retaliação futura, seja pela apreensão de uma suposta vigilância contínua por parte do tráfico e da polícia. A autora passa então a articular a categoria nativa da "tranquilidade" do Pereirão com a noção de silenciamento que, em suas observações, constitui o outro lado da moeda desta "tranquilidade" sempre enunciada.

Atuando como uma versão local de "lei do silêncio", a "tranquilidade" expressa pelos moradores lhes serve de mecanismo de autoproteção, "pois, negando a presença do tráfico de drogas, evitam ser vistos pelos não moradores de favela como coniventes". Tal configuração 
representa para a autora um paradoxo desumano porque, "submetendo-se ao próprio dispositivo que os oprime, os moradores do Pereirão conseguem evitar a sua desqualificação moral por conivência, mas não conseguem denunciar potenciais ameaças à sua segurança" (:93).

O capítulo 2 é dedicado à Associação de Moradores do Pereirão e às estratégias de atuação que seus dirigentes constroem dentro e fora do território da favela neste cenário particular de silenciamento. Para tanto, são apresentadas as gestões de dois dirigentes: Antônio, cujo trabalho à frente da Associação de Moradores foi mais detidamente acompanhado pela autora, e Lúcia, que assumiu o comando da Associação quando a pesquisa já se encontrava em fase de conclusão. O capítulo ainda faz uso de relatos coletados em grupos focais (também chamados no livro, por seu método de composição, de "coletivos de confiança") para uma pesquisa paralelamente realizada pela autora, como forma de ampliar o âmbito de análise das observações coletadas no trabalho de campo feito na favela do Pereirão. Em especial, são utilizadas falas de lideranças e dirigentes de associações de moradores de outras favelas da cidade, que servem metodologicamente à autora como dispositivos de generalização das observações colhidas no Pereirão. A inserção desses novos "interlocutores" no bojo da pesquisa também permite que dialogue com maior propriedade com a literatura sobre as associações de moradores em favelas, enfrentando especificamente as limitações e as delicadezas impostas a estes atores pela presença de grupos armados ligados ao tráfico de drogas.

Acompanhando boa parte da literatura citada, a autora torna evidente a dificuldade que as associações e suas lideranças enfrentam para manter suas organizações distantes do tráfico (:147). Complexificando, porém, o referencial teórico com o qual trabalha, as conclusões próprias da pesquisa apontam para a existência de certo grau de autonomia em algumas situações. A extensão da distância possível entre as associações, os dirigentes e o tráfico mostra-se variável. No caso da gestão de Antônio à frente da Associação de Moradores do Pereirão, o preço a ser pago pela distância foi a paralisia da associação.

O imobilismo da associação de moradores decorre de uma combinação de fatores explorados pela autora: falta de capital político de seu dirigente, ausência de "apadrinhamento" político em troca de benefícios públicos aos moradores, sua dificuldade em mediar conflitos envolvendo o tráfico e também entre os próprios moradores - e, em especial, a necessidade de distanciamento em relação ao tráfico de drogas que, em certa medida, reforçaria externamente a falta de "contaminação" e a identificação com as atividades criminosas. Embora este distanciamento pudesse representar, em tese, maior autonomia na gestão da Associação de Moradores, a autora dá algumas pistas de como a "tranquilidade" seria também e paradoxalmente um obstáculo à ação coletiva no Pereirão: a "tranquilidade" em função da falta de conflitos violentos também faz com que a localidade seja preterida no que se refere aos investimentos públicos, seguindo a lógica de que as ações sociais executadas pelo governo ou pelo terceiro setor privilegiam as "estratégias para a prevenção do crime" (:113) - enquadramento que decorre da identificação atual do "problema" da favela como um problema de segurança pública.

Já a gestão de Lúcia à frente da Associação de Moradores da favela, embora acompanhada brevemente pela autora, revela um melhor ajustamento aos atuais "tempos da política na favela" (:126). A categoria ajustamento é utilizada para se 
referir a uma maior ou menor adequação das organizações e dos dirigentes ao enquadramento atual do tema da favela (:45). Lúcia estaria mais "ajustada" a esses novos tempos porque conseguiria manejar formas de fazer política mais condizentes com o momento atual, lançando mão de estratégias parecidas com as utilizadas pelas organizações não governamentais que atuam em favelas.

No capítulo 3, este novo ator da política na favela entra definitivamente em cena. A autora descreve a formação e a atuação da ONG "TV Morrinho", criada no âmbito da favela do Pereirão a partir de uma iniciativa cultural de jovens moradores. A iniciativa começou com uma "brincadeira", quando um grupo de jovens amigos passou a construir maquetes representando as favelas da cidade, e nelas encenavam histórias do cotidiano dos moradores - e histórias sobre violência, a dinâmica do tráfico de drogas, suas relações e seus confrontos com policiais. A maquete tem cerca de $300 \mathrm{~m}^{2}$. A obra vistosa e o "realismo" das encenações tornaram o projeto mundialmente conhecido. A parceria com produtores de vídeo de fora da favela deu um salto de profissionalização à "brincadeira", e a TV Morrinho constituiu-se, então, como ONG.

Ao contar a história da TV Morrinho e ao descrever os formatos de sua atuação local e extralocal, a autora dá os primeiros passos na argumentação central de seu trabalho: o melhor "ajustamento" das organizações não governamentais aos formatos atuais do fazer político na favela. Primeiramente, porque a ONG fornece uma espécie de proteção e "limpeza moral" aos seus integrantes: inseridos em um "projeto social", os jovens moradores de favelas evitam a sua identificação com o tráfico e o mundo do crime. Esta melhor adequação também se reflete na linguagem utilizada pelas ONGs, manejada como forma de acesso a recursos e financiadores. No caso da TV Morrinho, as encenações "realistas" da vida na favela conseguem tematizar a violência urbana de forma abstrata e generalizada (:213), como algo que se passa fora do cotidiano próprio dos moradores, ajustando-se, assim, ao enquadramento atual do "problema" da favela sem quebrar o silenciamento que lhes é imposto.

E é a partir da apresentação deste cenário e destas práticas que a autora adentra o capítulo 4, de grande densidade teórica. Ela discorre com propriedade sobre o percurso de formação dos "novos movimentos sociais" e de consolidação de organizações que agem "em parceria com empresas privadas e com o Estado", articulando a disputa no campo simbólico que perpassa este momento político de legitimação de "novos problemas" no espaço público (: 232) para referi-los também ao espaço da favela e às organizações ali atuantes. Enquanto as associações de moradores apresentam demandas coletivas ao poder público, atuando sob a chave da carência, as ONGs - que não detêm funções públicas de representação dos moradores - podem transitar com mais facilidade em outras temáticas, inclusive reforçando a imagem positiva da favela, cotejando-a - em cada caso e na medida necessária - com o enquadramento da violência urbana.

A autora localiza, então, o duplo "ajustamento" das ONGs em face do atual enquadramento do "problema da favela", tanto pelo formato quanto pelo conteúdo (:236). Ajustam-se quanto ao formato porque possuem atributos de flexibilidade condizentes com o "novo espírito do capitalismo" ou "Cité par Projet": financiam-se e atuam através de projetos, com grande rotatividade de trabalhadores, firmando parcerias com o Estado e com empresas privadas para a consecução de políticas "focalizadas", em lugar de políticas universalistas. 
As ONGs ajustam-se também quanto ao conteúdo dos projetos executados - o que, no caso das favelas cariocas, reflete-se na ambivalência de representações que são capazes de articular, tematizando a violência urbana para se adequarem ao atual enquadramento do "problema da favela" (e terem acesso aos financiamentos necessários), mas também promovendo um discurso positivo sobre as favelas.

O movimento argumentativo da autora é coroado quando conclui que o duplo ajustamento das ONGs torna essas organizações a voz que fala pelas favelas perante o espaço público. Sendo esta, porém, uma "voz ajustada", ela representa uma outra dimensão do silenciamento imposto aos moradores das favelas, seja pela ausência de representatividade, seja por sua incapacidade estrutural de articular críticas ativas ao sistema, sem fazer frente às violações cotidianas e à situação de submissão dos moradores a um regime de violência.

Ao analisar o sentido da "tranquilidade" no Pereirão e por esta chave captar as percepções e as rotinas dos moradores no cotidiano da favela, o livro se torna parte imprescindível de uma bibliografia voltada para a compreensão do histórico de estratégias de ação coletiva empreendidas por moradores e organizações que atuam nas favelas cariocas. Como enuncia Machado da Silva na apresentação do livro (:10), a particularidade do Pereirão torna-se, pelas mãos de Lia Rocha, um caso "bom para pensar" a hipótese de silenciamento no conjunto de favelas da cidade. Trata-se de uma obra fundamental aos que hoje se dedicam a compreender novas configurações de atuação política nas favelas, especialmente após a implementação das Unidades de Polícia Pacificadora e a multiplicação das ditas rotinas de "tranquilidade" (ou de "paz", para utilizar a categoria nativa atual), e suas respectivas formas de silenciamento. 